\title{
SIMS Analysis: \\ Development and OSTI \\ Evaluation \\ Program Summary
}

RECEIVED

G. S. Groenewold

A. D. Appelhans

J. C. Ingram

J. E. Delmore

D. A. Dahl

DISTRIBUTION OF THIS DOCUMENT IS UNLAMTED u

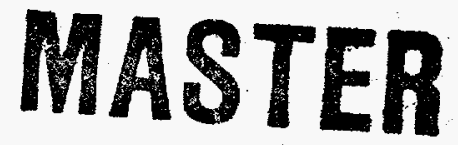

LOCKHEED MATTIN 


\section{DISCLAIMER}

Portions of this document may be illegible in electronic image products. Images are produced from the best available original document. 


\section{DISCLAIMER}

This report was prepared as an account of work sponsored by an agency of the United States Government. Neither the United States Government nor any agency thereof, nor any of their employees, makes any warranty, express or implied, or assumes any legal liability or responsibility for the accuracy, completeness, or usefulness of any information, apparatus, product, or process disclosed, or represents that its use would not infringe privately owned rights. Reference herein to any specific commercial product, process, or service by trade name, trademark, manufacturer, or otherwise does not necessarily constitute or imply its endorsement, recommendation, or favoring by the United States Government or any agency thereof. The views and opinions of authors expressed herein do not necessarily state or reflect those of the United States Government or any agency thereof. 


\section{SIMS Analysis: Development and Evaluation Program Summary}

INEL-96/0431

G. S. Groenewold

A. D. Appelhans

J. C. Ingram

J. E. Delmore

D. A. Dahl

Published November, 1996

Idaho National Engineering Laboratory Lockheed Idaho Technologies Corporation Idaho Falls, Idaho 83415

Prepared for the

U. S. Department of Energy

DOE Office of Technology Development

Under DOE Idaho Operations Office

Contract DE-AC07-94ID13223 


\section{SIMS Analysis: Development and Evaluation Program Summary}

G. S. Groenewold

A. D. Appelhans

J. C. Ingram

J. E. Delmore

D. A. Dahl

Published November, 1996

Idaho National Engineering Laboratory Lockheed Idaho Technologies Corporation Idaho Falls, Idaho 83415

Prepared for the

U. S. Department of Energy

DOE Office of Technology Development

Under DOE Idaho Operations Office

Contract DE-AC07-94ID13223 
SIMS Analysis: Development and Evaluation

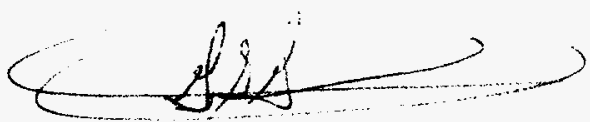

Gary S. Groenewold

Chemical and Materials Processes, Lockheed Idaho

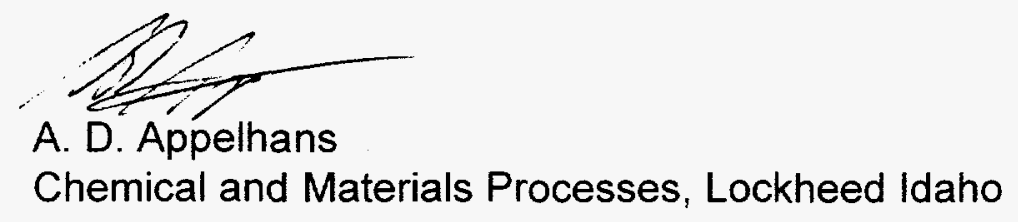

$10 / 30 / 96$

Date

$10 / 30 / 96$

Date 


\begin{abstract}
This report provides an overview of the "SIMS Analysis: Development and Evaluation Program," which was executed at the Idaho National Engineering Laboratory from mid-FY-92 to the end of FY-96. It should be noted that prior to FY-1994 the name of the program was "In-Situ SIMS Analysis". This report will not go into exhaustive detail regarding program accomplishments, because this information is contained in annual reports which are referenced herein. In summary, the program resulted in the design and construction of an ion trap secondary ion mass spectrometer (IT-SIMS), which is capable of the rapid analysis of environmental samples for adsorbed surface contaminants. This instrument achieves efficient secondary ion desorption by use of a molecular, massive $\mathrm{ReO}_{4}{ }^{-}$primary ion particle. The instrument manages surface charge buildup using a self-discharging principle, which is compatible with the pulsed nature of the ion trap. The instrument can achieve high selectivity and sensitivity using its selective ion storage and MS/MS capability. The instrument was used for detection of tri- $n$-butyl phosphate, salt cake (tank cake) characterization, and toxic metal speciation studies (specifically mercury). Technology transfer was also an important component of this program. The approach that was taken toward technology transfer was that of component transfer. This resulted in transfer of data acquisition and instrument control software in FY-94, and ongoing efforts to transfer primary ion gun and detector technology to other manufacturers.
\end{abstract}




\section{SUMMARY}

A program entitled "SIMS Analysis: Development and Evaluation Program," was conducted at the Idaho National Engineering Laboratory from mid-FY-92 to the end of FY-96. It should be noted that prior to FY-1994 the name of the program was "In-Situ SIMS Analysis". The program had three broad objectives, which were

1. Demonstration of secondary ion mass spectrometry (SIMS) for chemical detection and sample characterization applications.

2. Design and fabrication of new SIMS instrumentation based upon INEL SIMS and ion trap technology.

3. Technology transfer of instrument components to manufacturers and end users.

These three objectives will be discussed sequentially.

\section{Demonstration of secondary ion mass spectrometry (SIMS) for chemical detection and sample characterization applications.}

The program was initially focused on the detection of tri-n-butyl phosphate (TBP); this compound is significant in the DOE complex because it is used for Uranium extraction from nitric acid solutions. SIMS was demonstrated to be well suited to the detection of TBP on soil and basalt samples. Initial studies suggested that quantities substantially less than one monolayer could be detected. After FY-1993, TBP ceased to be of interest to DOE-OTD; however, the progress that had been made was valuable to another DOE office, and in a follow-on program, the detection of quantities approaching 0.001 monolayer were demonstrated.

In FY-1994, the emphasis of the chemical detection work shifted to the characterization of "salt cake", which is a waste form typical of what is encountered in high-level radioactive waste tanks. The initial soil and rock analyses that had been conducted in the TBP studies suggested that salt materials could be characterized using SIMS. A collaborative study with PNNL and Charles Evans \& Associates (Redwood City, CA) was initiated. SIMS instrumentation at INEL was shown to give excellent molecular information bearing on the nitrate/nitrite, and ferro-/ferricyanide composition of the salt cake samples. These parameters were particularly important for the estimation of the chemical energy in the chemical content of the tank waste. After FY-94, characterization of salt cake ceased to be of interest to DOE-OTD; however, the progress that was made was critical to ion gun transfer efforts that were conducted in FY-96. The results also indicated that a variety of organometallic species could be observed on surfaces, and hence were suggestive of a strategy for metal speciation. 
In FY-1995, the emphasis of the chemical detection work shifted once again, this time to the identification of toxic metal speciation. An end user was identified at the INEL, this group working on the remediation of the acid pit at the Radioactive Waste Management Complex. Research conducted using $\mathrm{Hg}$ salts showed that if the salts were exposed to gas-phase ligands that ionic, gas-phase $\mathrm{Hg}$-bearing ions could be observed. Furthermore, these species were indicative of the nature of the $\mathrm{Hg}$ species originally present on the surface of the sample. This result suggested an entirely new approach to toxic metal speciation.

\section{Design and fabrication of new SIMS instrumentation based upon INEL SIMS and ion trap technology.}

The program also went through several phases of instrument design, fabrication and testing. In FY-1992, quadrupole-based SIMS instrumentation was fabricated and dedicated to chemical applications testing. Beginning in FY-1993, design work was initiated for fabrication of an ion trap SIMS instrument. This resulted in construction of the ion trap SIMS in FY-1994, with the bulk of the testing in FY-1995. These activities resulted in the design and construction of an ion trap secondary ion mass spectrometer (IT-SIMS), which is capable of the rapid analysis of environmental samples for adsorbed surface contaminants. This instrument achieves efficient secondary ion desorption by use of a molecular, massive $\mathrm{ReO}_{4} \cdot$ primary ion particle. The instrument manages surface charge buildup using a self-discharging principle, which is compatible with the pulsed nature of the ion trap. The instrument can achieve high selectivity and sensitivity using its selective ion storage and MS/MS capability. The instrument was used for detection of tri- $n$-butyl phosphate, salt cake (tank cake) characterization, and toxic metal speciation studies (specifically mercury).

\section{Technology transfer of instrument components to manufacturers and end users.}

Technology transfer was also an important component of this program. The approach that was taken toward technology transfer was that of component transfer. This resulted in transfer of data acquisition and instrument control software in FY-94. In FY-96, non-disclosure agreements were reached with Teledyne, which permits pursuit of a collaborative effort for the design and fabrication of ion trap SIMS instruments, which may eventually be constructed by that company. In addition, beam comparison studies were performed in pursuit of transferring the $\mathrm{ReO}_{4}{ }^{-}$primary ion gun technology to Charles Evans \& Associates. This research was conducted in FY-96, and demonstrated that compared to $\mathrm{Cs}^{+}, \mathrm{ReO}_{4}^{-}$was at least 4 times more efficient at producing ionically bound, inorganic adduct ions.

The ion trap SIMS instrumentation developed under the DOE-OTD program is being transferred to the U. S. Army Chemical Materiel Destruction Activity, Non- 
Stockpile Program. The instrumentation is uniquely suited for the applications to be encountered by this program, because many of the contaminants which will be encountered are involatile, ionic, and highly surface active. These attributes render these compounds very difficult to detect using conventional

extraction/analysis methods; in contrast, they are highly amenable to detection using the ion trap SIMS. 
Contents

\begin{tabular}{|c|c|}
\hline Page & Section \\
\hline iii & Abstract \\
\hline iv & Summary \\
\hline vii & Contents \\
\hline vii & Tables \\
\hline vii & Figures \\
\hline viii & Acronyms and Symbols \\
\hline 1 & 1.0 Introduction \\
\hline 1 & 2.0 CHEMICAL APPLICATIONS STUDIES USING SIMS \\
\hline 1 & 2.1 Detection of Tri-n-butylphosphate (TBP) \\
\hline 2 & 2.2. Characterization of Salt Cake Samples \\
\hline 2 & 2.3 Mercury Speciation \\
\hline 2 & 3.0 DEVELOPMENT OF THE ION TRAP SIMS \\
\hline 3 & 4.0 TECHNOLOGY TRANSFER \\
\hline 3 & 5.0 CONCLUSIONS \\
\hline 4 & REFERENCES \\
\hline 5 & $\begin{array}{l}\text { Appendix 1. "Secondary lon Mass Spectrometry of Sodium Nitrate: } \\
\text { Comparison of } \mathrm{ReO}_{4} \text { and } \mathrm{Cs}^{+} \text {Primary lons" }\end{array}$ \\
\hline
\end{tabular}

Tables

\begin{tabular}{|c|l|}
\hline Page & Table \\
\hline 17 & Table 1. Identification of ions in the SIMS spectra of $\mathrm{NaNO}_{3}$. \\
\hline 18 & $\begin{array}{l}\text { Table 2. Comparison of secondary ion response per incident primary } \\
\text { ion, and disappearance corss sections }(\sigma), \text { using } \mathrm{ReO}_{4}\end{array}$ \\
\hline
\end{tabular}

\section{Figures}

\begin{tabular}{|c|l|}
\hline Page & Figure \\
\hline 20 & $\begin{array}{l}\text { Figure 1. Schematic diagram of the triple quadrupole SIMS instrument } \\
\text { equipped with } \mathrm{ReO}_{4}^{-} \text {and } \mathrm{Cs}^{+} \text {primary ion guns. }\end{array}$ \\
\hline 21 & $\begin{array}{l}\text { Figure 2a. Cation spectrum of } \mathrm{NaNO}_{3} \text { collected at low dose }(1 \mathrm{e} 12 \\
\left.\text { ions } / \mathrm{cm}^{2}\right), \text { using } \mathrm{ReO}_{4}^{-} \text {. b. Anion spectrum of } \mathrm{NaNO}_{3} \text { collected at low } \\
\text { dose }\left(1 \mathrm{e} 12 \text { ions } / \mathrm{cm}^{2}\right) \text { using } \mathrm{ReO}_{4}^{-} .\end{array}$ \\
\hline 22 & $\begin{array}{l}\text { Figure 3. Behavior of } \mathrm{NaNO}_{3} \text { secondary ions generated by } \mathrm{ReO}_{4}^{-} \text {ion } \\
\text { bombardment. }\end{array}$ \\
\hline 23 & $\begin{array}{l}\text { Figure 4. Comparison of secondary ions/incident primary ion } \mathrm{cm}^{2} \text {. Dose } \\
\text { regime was approximately } 1 \times 10^{12} \text { ions/cm }{ }^{2} \text { for these measurements. }\end{array}$ \\
\hline 24 & $\begin{array}{l}\text { Figure 5. Normalized secondary ion abundance's plotted vs. Quadrupole } \\
\text { axis voltage. Polarity of the } \mathrm{m} / \mathrm{z} \text { 62- voltages are reversed; this permits } \\
\text { the data for this anion to be plotted with that of the cations. }\end{array}$ \\
\hline
\end{tabular}




\section{ACRONYMS and SYMBOLS}

\begin{tabular}{|c|c|}
\hline $\begin{array}{c}\text { Acronym or } \\
\text { Symbol }\end{array}$ & Definition \\
\hline$\AA$ & angstrom, $10^{-10}$ meters \\
\hline $\mathrm{amu}$ & atomic mass unit \\
\hline $\mathrm{Ar}$ & argon \\
\hline $\mathrm{Ba}$ & barium \\
\hline C & carbon \\
\hline $\mathrm{CA}$ & California \\
\hline $\mathrm{Cl}$ & chlorine \\
\hline $\mathrm{cm}$ & centimeters \\
\hline $\mathrm{CO}_{2}$ & carbon dioxide \\
\hline Cs & cesium \\
\hline DOE & Department of Energy \\
\hline EDTA & ethylenediamine tetraacetic acid \\
\hline Eu & europium \\
\hline $\mathrm{eV}$ & electron volts \\
\hline FY & fiscal year \\
\hline $\mathrm{Fe}$ & iron \\
\hline $\mathrm{Fe}(\mathrm{CN})_{6}^{-3}$ & ferricyanide \\
\hline $\mathrm{Fe}(\mathrm{CN})_{6}^{-4}$ & ferrocyanide \\
\hline $\mathrm{H}$ & hydrogen \\
\hline $\mathrm{Hg}$ & mercury \\
\hline INEL & Idaho National Engineering Laboratory \\
\hline IT & ion trap \\
\hline IT-SIMS & ion trap secondary ion mass spectrometer \\
\hline $\mathrm{keV}$ & kiloelectron volt \\
\hline$m / z$ & mass to charge ratio \\
\hline $\mathrm{mm}$ & millimeters \\
\hline MS & mass spectrometry \\
\hline MS/MS & mass spectrometry/mass spectrometry \\
\hline $\mathrm{Na}$ & sodium \\
\hline $\mathrm{Na}_{2} \mathrm{CO}_{3}$ & sodium carbonate \\
\hline $\mathrm{NaOH}$ & sodium hydroxide \\
\hline $\mathrm{NaNO}_{2}$ & sodium nitrite \\
\hline $\mathrm{NaNO}_{3}$ & sodium nitrate \\
\hline $\mathrm{NO}_{2}^{-}$ & nitrite \\
\hline $\mathrm{NO}_{3}^{-}$ & nitrate \\
\hline $\mathrm{O}$ & oxygen \\
\hline
\end{tabular}




\section{ACRONYMS and SYMBOLS, con't}

\begin{tabular}{|c|l|}
\hline $\begin{array}{c}\text { Acronym or } \\
\text { Symbol }\end{array}$ & Definition \\
\hline $\mathrm{P}$ & phosphorus \\
\hline $\mathrm{pA}$ & picoamperes \\
\hline $\mathrm{Re}$ & rhennium \\
\hline $\mathrm{ReO}_{4}^{-}$ & perrhenate \\
\hline$\sigma$ & cross section \\
\hline $\mathrm{SF}_{6}$ & sulfur hexafluoride \\
\hline $\mathrm{Si}$ & silicon \\
\hline $\mathrm{SIMS}$ & secondary ion mass spectrometry \\
\hline $\mathrm{TBP}$ & tributyl phosphate \\
\hline $\mathrm{V}$ & volts \\
\hline
\end{tabular}




\title{
SIMS Analysis: Development and Evaluation Program Summary
}

\author{
G. S. Groenewold, J. C. Ingram, A. D. Appelhans, J. E. Delmore, D. A. Dahl \\ Idaho National Engineering Laboratory
}

\subsection{INTRODUCTION}

The purpose of the title program was to develop static secondary ion mass spectrometry (SIMS) instrumentation and methodology capable of detecting the presence of trace quantities of metals and other low volatile analytes, and also identifying the chemical species of these contaminants. There were three broad objectives to the FY95 program, which are covered in the following sections:

2.0 Demonstrate applicability of SIMS to contaminant detection issues, specifically organophosphate detection, salt cake characterization, and mercury speciation.

3.0 Develop ion trap SIMS instrumentation to the point where it could be demonstrated.

4.0 Transfer SIMS components to private enterprise.

Since most of the scientific and technology development took place in prior years, these activities will only be briefly summarized here, with appropriate referencing to past reports and published studies. Somewhat more detail will be given to FY-1996 activities, primarily in appendix 1.

\subsection{CHEMICAL APPLICATIONS STUDIES USING SIMS}

\subsection{Detection of Tri-n-butylphosphate (TBP)}

Tri- $n$-butylphosphate (TBP) is a chemical that was widely used in the DOE complex for extraction of uranium nitrates from nitric acid solutions to organic solvents. This process is efficient for separating uranium from other chemical components of fuel. Since TBP was used in this fashion, the chemical is frequently found in environments contaminated with uranium. Hence, it was felt that the compound could be used as a bellwether for the presence of uranium.

In SIMS studies conducted at the INEL, the following behavior was demonstrated:

- TBP could be readily detected on mineral surfaces. ${ }^{1,2,3}$

- The SIMS spectrum of TBP was dependent on the chemical nature of the mineral surface. ${ }^{4}$ 
- In subsequent studies funded by another DOE office (but based on science initiated by DOE-OTD), TBP was detected using ion trap SIMS technology down to 0.06 monolayer. $^{5}$

\subsection{Characterization of Salt Cake Samples}

Salt cake is a waste form which is encountered in high level radioactive waste tanks on the Hanford reservation and at other locations within the DOE complex. The salt cake is typically very high in nitrates, but also contains other constituents such as ferricyanide, metals, ethylenediamine tetraacetic acid (EDTA), and radionuclides. The salt cake in the tanks can be extremely radioactive. Studies conducted on simulated salt cake led to the following conclusions: ${ }^{6}$

- Simulated salt cake samples could be rapidly characterized in a matter of minutes using SIMS.

- Nitrate/nitrite $\left(\mathrm{NO}_{3}{ }^{-} \mathrm{NO}_{2}{ }^{-}\right)$content could be assessed.

- Ferri- / ferrocyanide $\left(\mathrm{Fe}(\mathrm{CN})_{6}^{-3} / \mathrm{Fe}(\mathrm{CN})_{6}{ }^{-4}\right.$ could be assessed.

\subsection{Mercury Speciation}

Mercury was used as a catalyst in the nitric acid dissolution process used on nuclear reactor fuel rods. Mercury has become an environmental contaminant within the DOE complex. Different mercury species have different toxicities and different mobilities in the environment, and hence determination of mercury species is an important issue. Studies were conducted to differentiate mercury species on sample surfaces using the ion trap SIMS instrumentation. These studies led to the following conclusions:

- Inorganic mercury species could be distinguished by performing a surface derivatization using volatile but adsorptive organic ligands, and then identifying the ligands using SIMS. ${ }^{7}$

- The ion trap SIMS instrument is uniquely suited to the observation of these species. ${ }^{8}$

\subsection{DEVELOPMENT OF THE ION TRAP SIMS}

The ion trap SIMS instrument that was developed under this program has attributes which make it applicable to a wide variety of problems. A description of the instrument has been published in section 4.0 of reference 8 . Features of the instrument are:

- Instrument is cart-mounted, is transportable, and occupies a 4' $\times 3^{\prime}$ footprint. This includes requisite pumping and computer. 
- The instrument is based upon the commercially-available Teledyne 3DQ ion trap mass spectrometer.

- Collisional stabilization of thermodynamically fragile, higher mass molecular ions is a unique capability.

- Selected ion storage and mass spectrometry/mass spectrometry (MS/MS) capability, overcome chemical background problems associated with SIMS.

\subsection{TECHNOLOGY TRANSFER}

The primary effort for FY-1996 involved technology transfer of the OTD instrumentation to private industry and end users. Specific descriptions of the successful transfer of instrument control and data acquisition software to ExtrelMillipore (a manufacturer of quadrupole mass spectrometer instruments) can be found in references 6 and 8 .

Work toward transferring the $\mathrm{ReO}_{4}^{-}$primary ion gun from INEL to Phi-Evans (Eden Prairie, MN) were initiated in FY 95, and continued in 1996. The primary work involved a rigorous comparison of sputtering efficacy of $\mathrm{ReO}_{4}{ }_{4}$ with a conventional atomic primary particle (in the present case $\mathrm{Cs}^{+}$). A description of this work is found in attachment $1 .{ }^{9}$ This study showed that $\mathrm{ReO}_{4}{ }^{-}$was approximately four times more effective for sputtering ionic, molecular species, when compared to $\mathrm{Cs}^{+}$. These results were communicated to Dr. Bruno Schuler of Phi-Evans, and have resulted in additional studies which will compare sputtering efficacy using computer hard drives as samples.

Transfer of detector and ion gun components to Teledyne continued in FY96, primarily through another program funded by the U. S. Army. The Army is an end user of this technology, and is keenly interested in applying ion trap SIMS technology to the characterization of environmental samples which have been contaminated with chemical warfare agents. INEL is currently in the process of fabricating ion trap SIMS instruments for the Army, which will be tested at Dugway Proving Ground using contaminated samples.

\subsection{CONCLUSIONS}

The SIMS analysis project met its programmatic objectives, and was also highly successful from a scientific point of view. Four salient results of the program are ennumerated below:

1. An ion trap SIMS instrument was developed, which offers selective and sensitive surface analysis capability, and is to some degree transportable. This development resulted in a follow-on project funded by the U. S. Army for the development of a 'next-generation' ion trap SIMS instrument. 
2. Novel surface adsorption chemistry was identified. This chemistry was significant enough that it led to the initiation of three programs funded by other DOE offices and government agencies.

3. A methodology was developed for identifying chemical speciation on the top monolayer of surfaces. This application was used in direct support of the acid pit remediation being conducted at the Radioactive Waste Management Complex at INEL.

4. Technology was successfully transferred to Extrel-Millipore, and will eventually be transferred to Phi-Evans. Transfer to Teledyne may occur.

\subsection{REFERENCES}

1 Groenewold, G. S.; Appelhans, A. D.; Ingram, J. C.; Delmore, J. E.; Dahl, D. A.; "In Situ Secondary Ion Mass Spectrometry Analysis 1992 Summary Report," Department of Energy Report EGG-WTD-10507, January, 1993.

2 Groenewold, G. S.; Ingram, J. C.; Delmore, J. E.; Appelhans, A. D.; Dahl, D. A., J. Haz. Mats., 1995, 41, 359-70.

3 Groenewold, G. S.; Appelhans, A. D.; Ingram, J. C.; Delmore, J. E.; Dahl, D. A.; "In Situ Secondary Ion Mass Spectrometry Analysis 1993 Summary Report," Department of Energy Report EGG-WTD-11177, March, 1994.

4 Groenewold, G. S.; Ingram, J. C.; Delmore, J. E.; Appelhans, A. D., J. Am. Soc. Mass Spectrom., 1995, 6, 165 - 74.

5 Ingram, J. C.; Groenewold, G. S.; Appelhans, A. D.; Dahl, D. A.; Delmore, J. E.; "Detection Limit and Surface Coverage Determination for Tributyl Phosphate on Soils by Static SIMS," Anal. Chem., 1996, 68, 1309 - 16.

6 Groenewold, G. S.; Appelhans, A. D.; Ingram, J. C.; Delmore, J. E.; Dahl, D. A.; "SIMS Analysis: Development and Evaluation, 1994 Summary Report," Department of Energy Report INEL-94/0177, December, 1994.

7 Groenewold, G. S.; Appelhans, A. D.; Ingram, J. C.; Delmore, J. E.; Dahl, D. A. "Surface Derivatization of Inorganic Mercury: Formation of Bis(alkylamine)mercury Cations," J. Amer. Soc. Mass Spectrom., submitted.

8 Groenewold, G. S.; Appelhans, A. D.; Ingram, J. C.; Delmore, J. E.; Dahl, D. A.; "SIMS Analysis: Development and Evaluation, 1995 Summary Report," Department of Energy Report INEL-95/0526, October, 1995.

9 Groenewold, G. S.; Delmore, J. E.; Olson, J. E.; Appelhans, A. D.; Ingram, J. C.; Dahl, D. A., "Secondary lon Mass Spectrometry of Sodium Nitrate: Comparison of $\mathrm{ReO}_{4}^{-}$and $\mathrm{Cs}^{+}$Primary lons," Int. J. Mass Spectrom. Ion Proc., submitted. 
Appendix 1. "Secondary Ion Mass Spectrometry of Sodium Nitrate: Comparison of $\mathrm{ReO}_{4}{ }^{-}$and $\mathrm{Cs}^{+}$Primary lons,", G. S. Groenewold, J. E. Delmore, J. E. Olson, A. D. Appelhans, J. C. Ingram, D. A. Dahl, submitted to the International Journal of Mass Spectrometry and Ion Processes, October, 1996.

\begin{abstract}
The use of perrhenate (rhenium tetroxide, $\mathrm{ReO}_{4}{ }^{-}$) as a bombarding particle was compared with $\mathrm{Cs}^{+}$for its ability to generate molecular species from sodium nitrate. The purpose of the study was to quantitatively evaluate the enhancement in sputtering to be gained using a heavy molecular primary particle. It was found that $\mathrm{ReO}_{4}^{-}$is three to five times more efficient at generating ions such as $\mathrm{Na}_{2} \mathrm{NO}_{3}{ }^{+}$and $\mathrm{Na}\left(\mathrm{NO}_{3}\right)_{2}{ }^{-}$. The nitrate-bearing molecular ions were observed to decrease in intensity as primary ion dose increases; at the same time, nitrite-bearing ions were observed to increase. This observation is interpreted in terms of beam damage to the surface of the target. Disappearance cross sections $(\sigma)$ using $\mathrm{ReO}_{4}{ }^{-}$bombardment were measured at 960 and $690 \AA^{2}$ for $\mathrm{Na}_{2} \mathrm{NO}_{3}{ }^{+}$and $\mathrm{Na}\left(\mathrm{NO}_{3}\right)_{2}{ }^{-}$, respectively. $\sigma$ values measured using $\mathrm{Cs}^{+}$bombardment were slightly larger. These measurements show that for an equivalent area of the sample disrupted, $\mathrm{ReO}_{4}$ is more effective for the production of nitrate-bearing secondary ions, which increases the probability of completing a measurement before extensive beam damage occurs. Secondary ion energies were evaluated and shown to be comparable for the $\mathrm{ReO}_{4}^{-}$and $\mathrm{Cs}^{+}$ bombardment experiments; for this reason, sample charging is not deemed to be a significant factor in these experiments.
\end{abstract}




\subsection{INTRODUCTION}

Large, molecular primary particles have been used to enhance the production of secondary ions in static secondary ion mass spectrometry (SIMS) for some time. ${ }^{1,2}$ In an earlier study conducted in our laboratory, $\mathrm{SF}_{6}{ }^{\circ}$ was shown to be as much as 24 times more efficient at producing secondary ions than was $\mathrm{Cs}^{+}{ }^{3}$

More recently, SIMS instrumentation in our laboratory has employed $\mathrm{ReO}_{4}{ }^{-}$as a primary particle. ${ }^{4} \mathrm{ReO}_{4}{ }^{-}$has several advantages over $\mathrm{SF}_{6}{ }^{\circ}: 1$ ) it can be produced by merely heating a ceramic in vacuum; 2 ) it produces no gas load on the vacuum system; 3 ) it is more than 100 amu heavier than $\left.\mathrm{SF}_{6}{ }^{\circ} ; 4\right)$ it can be produced with greater intensity than $\mathrm{SF}_{6}{ }^{0} ; 5$ ) since it is ionic, it can be focused more easily than $\mathrm{SF}_{6}{ }^{\circ} ; 6$ ) since it carries two more electrons to the surface than a comparable positive ion, it is much easier to maintain charge neutrality on insulating surfaces. The present study gives a quantitative assessment of the efficacy of $\mathrm{ReO}_{4}{ }^{-}$by comparing it to a more conventional primary particle, $\mathrm{Cs}^{+}$. In this study, a $\mathrm{Cs}^{+}$-emitting zeolite gun and $\mathrm{a} \mathrm{ReO}_{4}{ }^{-}$primary ion gun were mounted on a SIMS instrument. The two ion guns were identical except for the polarity and the emitter material. This instrumental arrangement permitted a direct comparison of the two primary particles.

The system that was chosen for comparison was sodium nitrate, because when the compound is coated onto a SIMS target, it is electrically conductive, and hence will not charge up when irradiated using the $\mathrm{Cs}^{+}$beam. Beyond this practical experimental consideration, the characterization of nitrate salts has been a specific topic of interest in our laboratory because the salts are an important waste form at facilities within the U. S. Department of Energy complex. ${ }^{5}$ More generally, the study of the desorption ionization mass spectra of salts is of importance in identifying inorganic and organometallic species on solid surfaces. Impressive advances have been made in analysis of salt particles, using "on-the-fly" laser desorption/ionization mass spectrometry. 6.7 However, relating the identity of desorbed ions to chemical species actually present on 
solid surfaces can be difficult. Sodium nitrate is a good example of this difficulty: previous SIMS analyses showed that unless care was taken, the SIMS spectra would resemble sodium nitrite, ${ }^{8}$ and many of the secondary ions observed were identical to those sputtered from sodium hydroxide. Thus, an ancillary objective of the present study is to provide a second look into the bombardment-induced changes in the SIMS spectrum of sodium nitrate.

In this paper, the salient secondary ions arising from sodium nitrate are identified. The behavior of these ions under extended primary ion bombardment are described. The integrated secondary ion response for the characteristic secondary ions are calculated and compared for $\mathrm{ReO}_{4}{ }^{-}$and $\mathrm{Cs}^{+}$. Possible effects of secondary ion kinetic energy are considered. The data show that for producing sodium nitrate adduct ions, $\mathrm{ReO}_{4}{ }^{-}$is on the order of three to five times more effective than $\mathrm{Cs}^{+}$.

\subsection{EXPERIMENTAL}

\subsection{Instrumentation}

The instrument used in these studies is based on an Extrel (Pittsburgh, PA) triple quadrupole mass spectrometer with $16.8 \mathrm{~mm}$ rods and a mass range of $530 \mathrm{amu}$. The instrument is fitted with both $\mathrm{a} \mathrm{ReO}_{4}{ }^{-}$primary ion gun, and with a $\mathrm{Cs}^{+}$primary ion gun (Figure 1). The ion guns, which were designed in our laboratory, are virtually identical, consisting of an ion emitter, a three element electrostatic zoom lens, and beam steering electrodes immediately after the exit aperture of the lens. The $\mathrm{ReO}_{4}^{-}$primary ion emitter has been described previously, ${ }^{4}$ and the $\mathrm{Cs}^{+}$ion source was constructed in a similar manner substituting a Cs zeolite emitter ${ }^{9}$ in place of the $\mathrm{ReO}_{4}{ }^{-}$ceramic. Both ion guns were mounted on a 12 in. spherical vacuum chamber, at a $35^{\circ}$ angle relative to the axis of the secondary ion mass spectrometer. This placement of the primary guns allowed the primary beams to pass through the center of the spherical chamber. Micro channel plate image intensifiers were mounted directly opposite each ion gun for assessing focusing and beam positioning. Both guns were 
operated at an ion energy of $5.25 \mathrm{keV}$, with the primary ion current controlled to between 100 and 300 picoamperes.

The primary ion beam current was measured using a retractable, shielded Faraday cup. The Faraday cup could be inserted to a position co-linear with the axis of the secondary ion mass spectrometer, but just off center of the spherical chamber, so that the sample was positioned in the center of the sphere between the Faraday cup and the ion guns. This location allowed the Faraday cup to intercept both primary ion beams while providing room to insert the sample between the cup and the mass spectrometer. When the Faraday cup was retracted, the primary beams could be observed on the image intensifiers. The Faraday cup was held at ground potential through the electrometer. A grid was mounted near the entrance of the cup during measurement of the primary ion current. During the measurement of the primary ion current, the Faraday cup was biased at $-50 \mathrm{~V}$ to suppress any secondary electron emission from the cup. The primary ion current was stable to within $5 \%$ over the course of a single sodium nitrate analysis. During an analysis, the shielded Faraday cup was left in position behind the sample target, where it served as an electrostatic grid which helped to focus the sputtered ions toward the secondary ion lens. The voltage was alternated at plus or minus $10 \mathrm{~V}$, depending on whether secondary cations or anions were being analyzed.

Sample targets which were roughly rectangular were attached to a direct insertion probe. When the sample target was inserted, it intercepted the primary ion beam, which could be observed on the image intensifier. The focusing of the primary ion guns was adjusted such that the primary ion beam illuminated the full width of the sample target, but not the full length.

Identical secondary ion extraction voltages and sample target position were used for both the $\mathrm{ReO}_{4}^{-}$and for the $\mathrm{Cs}^{+}$bombardment experiments. To properly position the sample target, the following procedure was followed: the target was visually positioned in front of the secondary extraction lens, and then irradiated 
with the $\mathrm{ReO}_{4}^{-}$gun. The primary ion gun deflection electrodes were tuned such that the target was illuminated, as viewed on the image intensifier. Then the secondary ion extraction lens elements were tuned to maximize transmission of a secondary anion and cation (typically $\mathrm{m} / \mathrm{z} 62^{-}$and $62^{+}$). The $\mathrm{Cs}^{+}$gun was then focused on the target, using the same method. The position of the sample target, and the electrostatic focusing of both guns, were noted, and these were used throughout the study

The secondary ion extraction lens was operated in a "pulsed extraction" mode,$^{10}$ which means that anions and cations are alternately extracted from the secondary ion source. This extraction system, when coupled to the quadrupole mass analyzer, permits the acquisition of the anion and cation spectra in an interlaced fashion. The extraction time for each polarity was adjustable, and the ratio [cation extraction time/anion extraction time] used in the present experiments was 1.0. The actual time required for a single cation/anion extraction cycle was 50 milliseconds, divided as follows: 22 milliseconds cation extraction; 3 milliseconds electronics settle time; 22 milliseconds anion extraction time; 3 milliseconds electronics settle time.

\subsection{Measurement of Secondary lon Response and Decay.}

Since secondary ion response is a function of dose, it was necessary to know the fraction of the beam on target, and the area of the target irradiated. The fraction of the beam on target was measured as the difference between the primary ion current with the target in the path of the primary ion beam, and with the target retracted. Typical values for the portion of the beam on target ranged from 60 to $200 \mathrm{pA}$. The shape of the portion of the target actually in the beam was approximately rectangular; the width could be measured directly using a micrometer, and was always less than the diameter of the primary ion beam. The length of the target in the beam was measured by inserting the target until the primary ion current was just decreased, then inserting the target approximately $2 \mathrm{~mm}$ further; this dimension was then measured using the 
micrometer. Typical values for the area of the target in the beam were on the order of 0.03 to $0.04 \mathrm{~cm}^{2}$.

To compare secondary ion response, a single target was bombarded by one of the primary beams. The pulsed extraction acquisition cycle described above was repeated nine times and then averaged for every $0.2 \mathrm{amu}$ of a scan of the mass regions of interest. Thirty scans were collected for each acquisition, and the spectra were recorded individually in the data system.

\subsection{Assessment of Secondary lon Kinetic Energy Using $\mathrm{Cs}^{+}$and $\mathrm{ReO}_{4}{ }^{-}$}

A second type of experiment was performed to assess the kinetic energy of the secondary ions emitted under both $\mathrm{Cs}^{+}$and $\mathrm{ReO}_{4}{ }^{-}$bombardment. These experiments were performed to determine if surface charging was changing between $\mathrm{Cs}^{+}$and $\mathrm{ReO}_{4}{ }^{-}$bombardment. In the experiment, the quadrupole was scanned over a very narrow mass range, such that a single ion was transmitted, and the quadrupole axis voltage was gradually increased. When the axis voltage exceeded the kinetic energy of the secondary ions, the ions were no longer detected; thus the technique provided a measurement of the kinetic energy of the majority of the ions sputtered from the surface.

The efficacy of this technique was demonstrated in our laboratory using another quadrupole SIMS instrument in which the quadrupole axis voltage and the sample target voltage could be independently controlled. The technique can be illustrated by the following description of cation detection as a function of secondary ion energy. When a conducting sample was grounded, abundant cations could be observed. Subsequently the quadrupole axis voltage was increased above ground potential: the secondary cation abundance was observed to decrease dramatically. At a quadrupole axis voltage of $+1 \mathrm{~V}$, most of the secondary cation signal was gone, which indicates that most of the secondary ions have ion kinetic energies $<1 \mathrm{eV}$. The validity of this approach was checked by placing a $+5 \mathrm{~V}$ potential on the sample target, which has the effect of adding $5 \mathrm{eV}$ of kinetic energy to emitted secondary ions, relative to a 
grounded quadrupole. The quadrupole axis voltage was then increased. When the quadrupole axis voltage exceeded $+5 \mathrm{~V}$, the cation abundance decreased rapidly, thus confirming that the quadrupole axis voltage can be used to assess secondary ion kinetic energies.

\subsection{Sample Preparation}

Sodium nitrate (Fisher Scientific) was dissolved in distilled water, and then diluted such that the concentration was $19.8 \mu \mathrm{g} / \mu \mathrm{l}$. Two $\mu \mathrm{l}$ of this solution was applied to a stainless steel sample holder, with an area of 0.03 to $0.04 \mathrm{~cm}^{2}$, and allowed to dry at ambient temperature. This preparation would result in a surface concentration of approximately $10^{3}$ to $10^{4}$ monolayers, if an even deposition of sodium nitrate occurs. Once dry, the sample was attached to the direct insertion probe and analyzed. Microscopic examination (60X) of the dried sample revealed a glassy surface layer. A similar procedure was used for generating the sodium nitrite (Fisher Scientific) targets.

\subsection{RESULTS AND DISCUSSION}

\subsection{Secondary lons from $\mathrm{NaNO}_{3}$}

The cation spectrum of $\mathrm{NaNO}_{3}$ is dominated by $\mathrm{Na}^{+}$, but also contains abundant molecular species which are attributed to sodium oxide, sodium nitrate, and hydrocarbon species (Table 1). The anion spectrum contains very abundant $\mathrm{O}^{-}$and $\mathrm{OH}^{-}$, but as in the cation spectrum, significant nitrate-bearing ions are observed. In both the anion and cation spectra, ions arising from surface contaminants are observed. Examples are $\mathrm{m} / \mathrm{z} 73^{+}$and $147^{+}$(siloxane origin), and $79^{-}$(phosphate origin), and $35^{-}\left(\mathrm{Cl}^{-}\right)$. The spectrum presented in Figures $2 \mathrm{a}$ and $\mathrm{b}$ were acquired using $\mathrm{ReO}_{4}{ }^{\circ}$ as the bombarding particle, at a low primary ion dose (ca. $1 \times 10^{12}$ ions $/ \mathrm{cm}^{2}$ ). The spectra acquired using $\mathrm{ReO}_{4}{ }^{-}$were qualitatively the same as the spectra acquired using $\mathrm{Cs}^{+}$.

The spectra produced by both $\mathrm{ReO}_{4}{ }^{-}$and $\mathrm{Cs}^{+}$at low dose were indicative of the sodium nitrate in that the nitrate-bearing ion species were more abundant 
than nitrite-bearing species. In this respect, both $\mathrm{ReO}_{4} ;$, and $\mathrm{Cs}^{+}$spectra generated using a dose of $1 \times 10^{12}$ ions $/ \mathrm{cm}^{2}$ were similar to spectra reported by Marien and De Pauw using an $800 \mathrm{eV} \mathrm{Ar}{ }^{+}$primary beam. ${ }^{8}$ These authors reported a $\left[\mathrm{Na}_{2} \mathrm{NO}_{2}{ }^{+} / \mathrm{Na}_{2} \mathrm{NO}_{3}{ }^{+}\right]$ratio of 0.5 : in the present experiments, the average ratios were 0.8 using the $\mathrm{ReO}_{4}{ }^{-}$gun, and 0.4 using the $\mathrm{Cs}^{+}$gun. The difference between the $\mathrm{Cs}^{+}$and $\mathrm{ReO}_{4}{ }^{-}$guns indicates that $\mathrm{Cs}^{+}$bombardment produces a higher fraction of intact nitrate species at low dose (although the comparison studies presented below show that the absolute abundance is substantially lower with $\mathrm{Cs}^{+}$). This conclusion is in agreement with Hand, et al., who concluded that polyatomic primary ions produced more fragmentation, all other things being equal. ${ }^{2}$

\subsection{Behavior of $\mathrm{NaNO}_{3}$ lons with Increasing Primary lon Dose}

As the $\mathrm{ReO}_{4}{ }^{-}$dose is increased (Figure 3), the abundances of the nitratebearing adduct ion species (e.g., $\mathrm{Na}_{2} \mathrm{NO}_{3}{ }^{+}, \mathrm{Na}\left(\mathrm{NO}_{3}\right)_{2}{ }^{-}$) decrease, while the nitritebearing adduct ions (like $\mathrm{Na}_{2} \mathrm{NO}_{2}{ }^{+}, \mathrm{Na}\left(\mathrm{NO}_{2}\right)_{2}{ }^{-}$) either hold constant or slightly increase in abundance. The $\left[\mathrm{Na}_{2} \mathrm{NO}_{2}{ }^{+} / \mathrm{Na}_{2} \mathrm{NO}_{3}{ }^{+}\right]$ratio after a dose of $3 \times 10^{13}$ ions $/ \mathrm{cm}^{2}$ was 2.3 , which compares favorably with the value reported using 2.5 $\mathrm{keV} \mathrm{Ar}^{+}$bombardment. ${ }^{8}$ Similar behavior was recorded using $\mathrm{Cs}^{+}$as the primary ion beam, only the absolute ion abundances were lower.

The abundances of $\mathrm{Na}^{+}$and $\mathrm{NO}_{2}^{-}$were observed to increase substantially with primary ion dose. In contrast, the abundance of $\mathrm{NO}_{3}{ }^{-}$undergoes a pronounced decrease upon initiation of ion bombardment, and then appears to slowly decrease in abundance. These observations are largely consistent with a build up of $\mathrm{NO}_{2}^{-}$on the surface of the $\mathrm{NaNO}_{3}$ sample as a result of beam damage.

$M / z 129^{+}$observed in the spectrum of sodium nitrate also increases with primary ion dose. This ion corresponds to $\mathrm{Na}_{3} \mathrm{CO}_{3}{ }^{+}$, and is observed in abundance in the SIMS spectra of $\mathrm{Na}_{2} \mathrm{CO}_{3}, \mathrm{NaNO}_{2}$, and $\mathrm{NaOH}$. In the case of 
$\mathrm{NaNO}_{2}$ and $\mathrm{NaOH}$, it is believed that these basic salts fix $\mathrm{CO}_{2}$ from the atmosphere, which is then observable in the SIMS spectrum as $\mathrm{Na}_{3} \mathrm{CO}_{3}{ }^{+}$. Note that $\mathrm{NaNO}_{2}$ can be thought of as the salt of a strong base $(\mathrm{NaOH})$ and a weak acid $\left(\mathrm{HNO}_{2}\right)$. In contrast to $\mathrm{NaNO}_{2}, \mathrm{NaNO}_{3}$ is not a base, and at low dose does not produce an abundant $\mathrm{m} / \mathrm{z} 129^{+}$. The fact that $\mathrm{Na}_{3} \mathrm{CO}_{3}{ }^{+}$would increase in intensity during bombardment of $\mathrm{NaNO}_{3}$ was surprising. Carbonate may be present in the $\mathrm{NaNO}_{3}$ salt (a low abundance $\mathrm{m} / z 129^{+}$is observed at low dose), and formation of $\mathrm{NaCO}_{3}{ }^{+}$may be facilitated by abundant $\mathrm{Na}^{+}$on the surface, which results from beam damage. Alternatively, the formation of the stronger base $\mathrm{NO}_{2}^{-}$from beam damage may result in fixation of residual $\mathrm{CO}_{2}$ from the vacuum chamber.

\subsection{Comparison of $\mathrm{ReO}_{4}{ }^{-}$and $\mathrm{Cs}^{+}$for the Generation of Sodium Nitrate} Adduct lons.

When compared with $\mathrm{Cs}^{+}, \mathrm{ReO}_{4}^{-}$was found to be between three and five times more efficient at generating molecular secondary ions from sodium nitrate. This conclusion is based upon several comparisons. The integrated secondary ion response for the nitrate-bearing adducts $\mathrm{Na}_{2} \mathrm{NO}_{3}{ }^{+}$and $\mathrm{Na}\left(\mathrm{NO}_{3}\right)_{2}{ }^{-}$was compared over the dose regime from 0 to $1 \times 10^{13} \mathrm{ions} / \mathrm{cm}^{2}$. On average, $\mathrm{ReO}_{4}$. was 5.5 times more efficient for producing $\mathrm{Na}_{2} \mathrm{NO}_{3}{ }_{3}$, and 3.3 times more efficient for producing $\mathrm{Na}\left(\mathrm{NO}_{3}\right)_{2}^{-}$(Table 2). The abundance of molecular secondary ions was also compared after a dose of $1 \times 10^{12}$ ions $/ \mathrm{cm}^{2}$ (Figure 4): the average enhancement effected using $\mathrm{ReO}_{4}{ }^{-}$was three. When the abundance was compared after a dose of $1 \times 10^{13}$ ions $/ \mathrm{cm}^{2}$, the $\mathrm{ReO}_{4}{ }^{-}$enhancement was in excess of five, which indicates that $\mathrm{Cs}^{+}$is disrupting the surface at a greater rate than $\mathrm{ReO}_{4}^{-}$. This conclusion is supported by a comparison of the disappearance cross sections $(\sigma)$ measured for $\mathrm{Na}_{2} \mathrm{NO}_{3}{ }^{+}$and $\mathrm{Na}\left(\mathrm{NO}_{3}\right)_{2}{ }^{-}$using both $\mathrm{ReO}_{4}{ }^{-}$and $\mathrm{Cs}^{+}$(Table 2): the area disrupted using $\mathrm{Cs}^{+}$is somewhat larger than the area disrupted using $\mathrm{ReO}_{4}$. 
The fact that $\mathrm{ReO}_{4}{ }^{-}$has five times as many nucleii as $\mathrm{Cs}^{+}$suggests that this parameter may be responsible for the secondary ion enhancement. In other words, $\mathrm{ReO}_{4}{ }^{-}$is more efficient than $\mathrm{Cs}^{+}$merely because it has five times as many atoms hitting the surface. However, if this were the case, then one might expect that the surface area disrupted (i.e..,$\sigma$ ) would be greater for $\mathrm{ReO}_{4}^{-}$, which is opposite of what is observed. These data indicate that compared to $\mathrm{Cs}^{+}, \mathrm{ReO}_{4}{ }^{-}$ produces three to five times more adduct ions for the equivalent area perturbed. The increased mass of $\mathrm{ReO}_{4}{ }^{-}(250 \mathrm{amu})$ compared to $\mathrm{Cs}^{+}$(133 amu), certainly facilitates desorption: the effect of mass has previously been demonstrated in our lab, ${ }^{3}$ and by others. ${ }^{2}$

\subsection{Evaluation of Surface Charging}

A significant concern regarding the $\mathrm{Cs}^{+} / \mathrm{ReO}_{4}{ }^{-}$comparison is the possibility of surface charging, which can adversely affect secondary ion emission, which would, in turn, perturb the comparison of the two primary ions. Since surface charging will also affect the kinetic energy of the emitted secondary ion, the kinetic energy of selected ions was evaluated by increasing the quadrupole axis voltage in a stepwise manner until the secondary ions can no longer enter the quadrupole. If the profiles of abundance versus axis voltage for both anions and cations are significantly different, a substantial surface charge buildup would be indicated. This would invalidate the $\mathrm{Cs}^{+} / \mathrm{ReO}_{4}{ }^{-}$comparison, since negative primaries are much more effective at mitigating surface charging than are cations. $^{11}$

Ion abundance versus axis voltage plots are presented in Figure 5, for three different secondary ions, for both primary beams. As the quadrupole axis voltage is increased above ground, the potential exceeds the kinetic energy of

the secondary ions, and their abundance decreases rapidly. We emphasize that this decrease is not due to the energy acceptance of the secondary ion lens, which will accept ions over a wide range of kinetic energies without discrimination. 
Essentially no differences were observed in comparing the anion and cation profiles, or in comparing $\mathrm{Cs}^{+}$with $\mathrm{ReO}_{4}$. This is a good indication that no substantial surface charging is occurring during either $\mathrm{Cs}^{+}$or $\mathrm{ReO}_{4}^{-}$ bombardment. The ions chosen were $\mathrm{m} / \mathrm{z} 23^{+}\left(\mathrm{Na}^{+}\right)$, which represents an atomic cation, $\mathrm{m} / \mathrm{z} 62^{-}\left(\mathrm{NO}_{3}{ }^{-}\right)$, which represents a molecular anion, and $\mathrm{m} / \mathrm{z} 73^{+}$ $\left(\left(\mathrm{CH}_{3}\right)_{3} \mathrm{Si}^{+}\right)$, which represents a molecular cation. The latter ion is formed from trace levels of siloxane contaminants, which are commonly present on the sample surface. Both of the profiles generated for the atomic $\mathrm{Na}^{+}$display a somewhat longer "tail" at higher voltage, which is consistent with the fact that they are sputtered with a broader distribution of kinetic energy.

\subsection{CONCLUSIONS}

The comparison experiments performed on $\mathrm{NaNO}_{3}$ using both $\mathrm{ReO}_{4}{ }^{-}$and $\mathrm{Cs}^{+}$ ion bombardment show that $\mathrm{ReO}_{4}^{-}$effects an enhancement in the emission of molecular secondary ions which is on the order of three to five. At the same time, the area disrupted by $\mathrm{ReO}_{4}^{-}$, as evaluated by the disappearance cross sections for the nitrate-bearing secondary ions, is actually less than the area disrupted by $\mathrm{Cs}^{+}$. These measurements show that for an equivalent area of the sample disrupted, $\mathrm{ReO}_{4}{ }^{-}$is substantially more effective for the production of nitrate-bearing secondary ions. The measurements were shown not to be influenced by surface charging. It should be emphasized at this point that the conclusions above are based on the behavior of ionic adduct ions, and that they may not apply to organic surface contaminants which are of a covalent nature. These findings have motivated continuing investigations in our laboratory. 


\section{REFERENCES}

1 M. G. Blaine, S. Della-Negra, J. Joret, Y. Le Beyec, and E. A. Schweikert, Journal de Physique, 50 (1989) C2-147.

2 O. W. Hand, T. K. Majumdar, and R. G. Cooks, Int. J. Mass Spectrom. Ion Proc., 97 (1990) 35.

3 A. D. Appelhans and J. E. Delmore, Anal. Chem., 61 (1989) 1087.

4 a. J. E. Delmore, A. D. Appelhans, and E. S. Peterson, Int. J. Mass Spectrom. Ion Processes, 146/147 (1995) 15. b. J. E. Delmore, A. D. Appelhans, and E. S. Peterson, Int. J. Mass Spectrom. Ion Processes, 108 (1991) 179.

5 a. S. J. Bajic, S. Luo, R. W. Jones, and J. F. McClelland, Applied Spectroscopy, 49 (1995) 1000. b. J. A. Campbell, R. W. Stromatt, M. R. Smith, D. W. Koppenaal, R. M. Bean, T. W. Jones, D. M. Strachan, and H. Babad, Anal. Chem., 66 (1994) 1208A.

6 M. V. Johnston and A. S. Wexler, Anal. Chem., 67 (1995) 721A.

7 T. Nordmeyer and K. Prather, Anal. Chem., 66 (1994) 3540.

8 J. Marien and E. De Pauw, E. Int. J. Mass Spectrom. Ion Processes, 43 (1982) 233.

9 S. T. Beck, D. W. Warner, B. F. Garland and F. W. Wells, Rev. Sci. Instrum., 60 (1989) 2653.

${ }^{10}$ A. D. Appelhans, D. A. Dahl and J. E. Delmore, Anal. Chem., 62 (1990) 1679.

${ }^{11}$ C. A. Anderson, H. J. Roden and C. F. Robinson, J. Appl. Phys., 40 (1969) 3419. 


\begin{tabular}{|l|l|l|l|}
\hline \multicolumn{4}{|l|}{ Table 1. Identification of ions in the SIMS spectra of $\mathrm{NaNO}_{3}$} \\
\hline cation mass & composition & anion mass & composition \\
\hline $147^{+}$ & $\left(\mathrm{CH}_{3}\right)_{3} \mathrm{SiO}\left(\mathrm{CH}_{3}\right)_{2} \mathrm{Si}^{+}$ & $147^{-}$ & $\mathrm{Na}\left(\mathrm{NO}_{3}\right)_{2}^{-}$ \\
\hline $145^{+}$ & $\mathrm{Na}_{3} \mathrm{CO}_{4}^{+}$ & $131^{-}$ & $\mathrm{Na}\left(\mathrm{NO}_{3}\right)\left(\mathrm{NO}_{2}\right)^{-}$ \\
\hline $129^{+}$ & $\mathrm{Na}_{3} \mathrm{CO}_{3}^{+}$ & $115^{-}$ & $\mathrm{Na}\left(\mathrm{NO}_{2}\right)_{2}^{-}$ \\
\hline $108^{+}$ & $\mathrm{Na}_{2} \mathrm{NO}_{3}^{+}$ & $79^{-}$ & $\mathrm{PO}_{3}^{-}$ \\
\hline $101^{+}$ & $\mathrm{Na}_{3} \mathrm{O}_{2}^{+}$ & $62^{-}$ & $\mathrm{NO}_{3}^{-}$ \\
\hline $92^{+}$ & $\mathrm{Na}_{2} \mathrm{NO}_{2}^{+}$ & $46^{-}$ & $\mathrm{NO}_{2}^{-}$ \\
\hline $85^{+}$ & $\mathrm{Na}_{3} \mathrm{O}^{+}$ & $45^{-}$ & $\mathrm{HCO}_{2}^{-}$ \\
\hline $78^{+}$ & $\mathrm{Na}_{2} \mathrm{O}_{2}^{+}$ & $35^{-}$ & $\mathrm{Cl}^{-}$ \\
\hline $73^{+}$ & $\left(\mathrm{CH}_{3}\right)_{3} \mathrm{Si}^{+}$ & $17^{-}$ & $\mathrm{OH}^{-}$ \\
\hline $63^{+}$ & $\mathrm{Na}_{2} \mathrm{OH}^{+}$ & $16^{-}$ & $\mathrm{O}^{-}$ \\
\hline $62^{+}$ & $\mathrm{Na}_{2} \mathrm{O}^{+}$ & & \\
\hline $23^{+}$ & $\mathrm{Na}^{+}$ & & \\
\hline
\end{tabular}


Table 2. Comparison of secondary ion response per incident primary ion, and disappearance cross sections $(\sigma)$, using $\mathrm{ReO}_{4}{ }^{-}$and $\mathrm{Cs}^{+}$. Values for secondary counts/ion and cross sections represent the average of three analyses. The absolute number of secondary counts is arbitrary and does not take into account the efficiency of the secondary ion mass spectrometer.

\begin{tabular}{|l|l|l|c|l|l|}
\hline $\begin{array}{l}\text { secondary } \\
\text { ion }\end{array}$ & $\begin{array}{l}\text { secondary } \\
\text { counts/ } \\
\mathrm{ReO}_{4}^{-}\end{array}$ & $\begin{array}{l}\text { secondary } \\
\text { counts/Cs }\end{array}$ & factor & $\begin{array}{l}\sigma, \AA^{2}, \\
\text { measured } \\
\text { with } \mathrm{ReO}_{4}^{-}\end{array}$ & $\begin{array}{l}\sigma_{1} \AA^{2}, \\
\text { measured } \\
\text { with } \mathrm{Cs}^{+}\end{array}$ \\
\hline $\mathrm{Na}_{2} \mathrm{NO}_{3}^{+}$ & $2.3 \times 10^{-7}$ & $5.1 \times 10^{-8}$ & 4.5 & 960 & 1300 \\
\hline $\mathrm{Na}\left(\mathrm{NO}_{3}\right)_{2}^{-}$ & $1.8 \times 10^{-7}$ & $5.9 \times 10^{-8}$ & 3.1 & 690 & 1100 \\
\hline
\end{tabular}


Figure Captions for "Secondary Ion Mass Spectrometry of Sodium Nitrate: Comparison of $\mathrm{ReO}_{4}{ }^{-}$and $\mathrm{Cs}^{+}$Primary lons," G. S. Groenewold, et al.

Figure 1. Schematic diagram of the triple quadrupole SIMS instrument equipped with $\mathrm{ReO}_{4}^{-}$and $\mathrm{Cs}^{+}$primary ion guns.

Figure 2a. Cation spectrum of $\mathrm{NaNO}_{3}$ collected at low dose $\left(1 \mathrm{e} 12 \mathrm{ions} / \mathrm{cm}^{2}\right)$, using $\mathrm{ReO}_{4}$.

Figure $2 \mathrm{~b}$. Anion spectrum of $\mathrm{NaNO}_{3}$ collected at low dose $\left(1 \mathrm{e} 12 \mathrm{ions} / \mathrm{cm}^{2}\right)$ using $\mathrm{ReO}_{4}$.

Figure 3. Behavior of $\mathrm{NaNO}_{3}$ secondary ions generated by $\mathrm{ReO}_{4}^{-}$ion bombardment.

Figure 4. Comparison of secondary ions/incident primary ion $\mathrm{cm}^{2}$. Dose regime was approximately $1 \times 10^{12}$ ions $/ \mathrm{cm}^{2}$ for these measurements.

Figure 5. Normalized secondary ion abundance's plotted vs. Quadrupole axis voltage. Polarity of the $\mathrm{m} / \mathrm{z} 62^{-}$voltages are reversed; this permits the data for this anion to be plotted with that of the cations. 


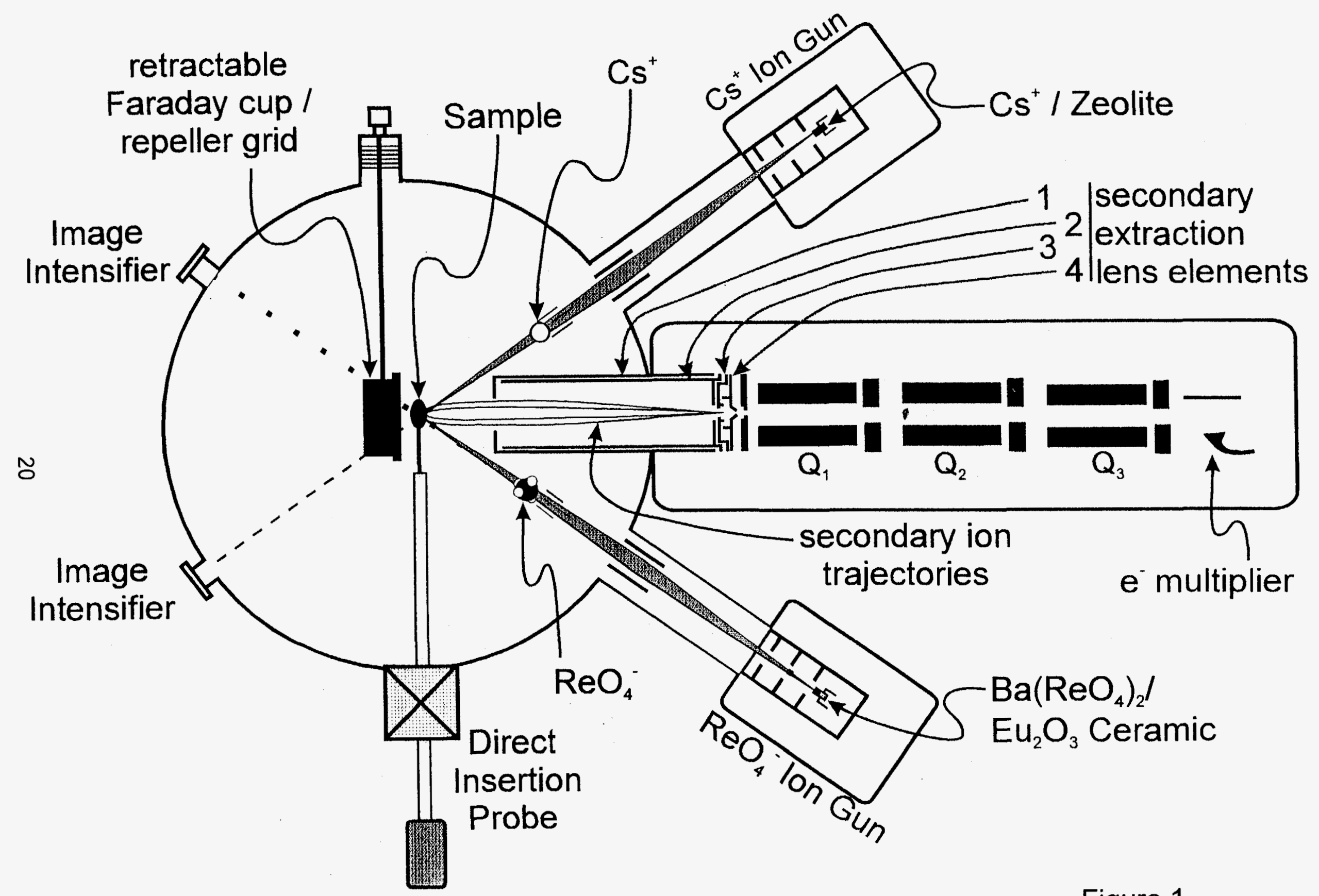

Figure 1 

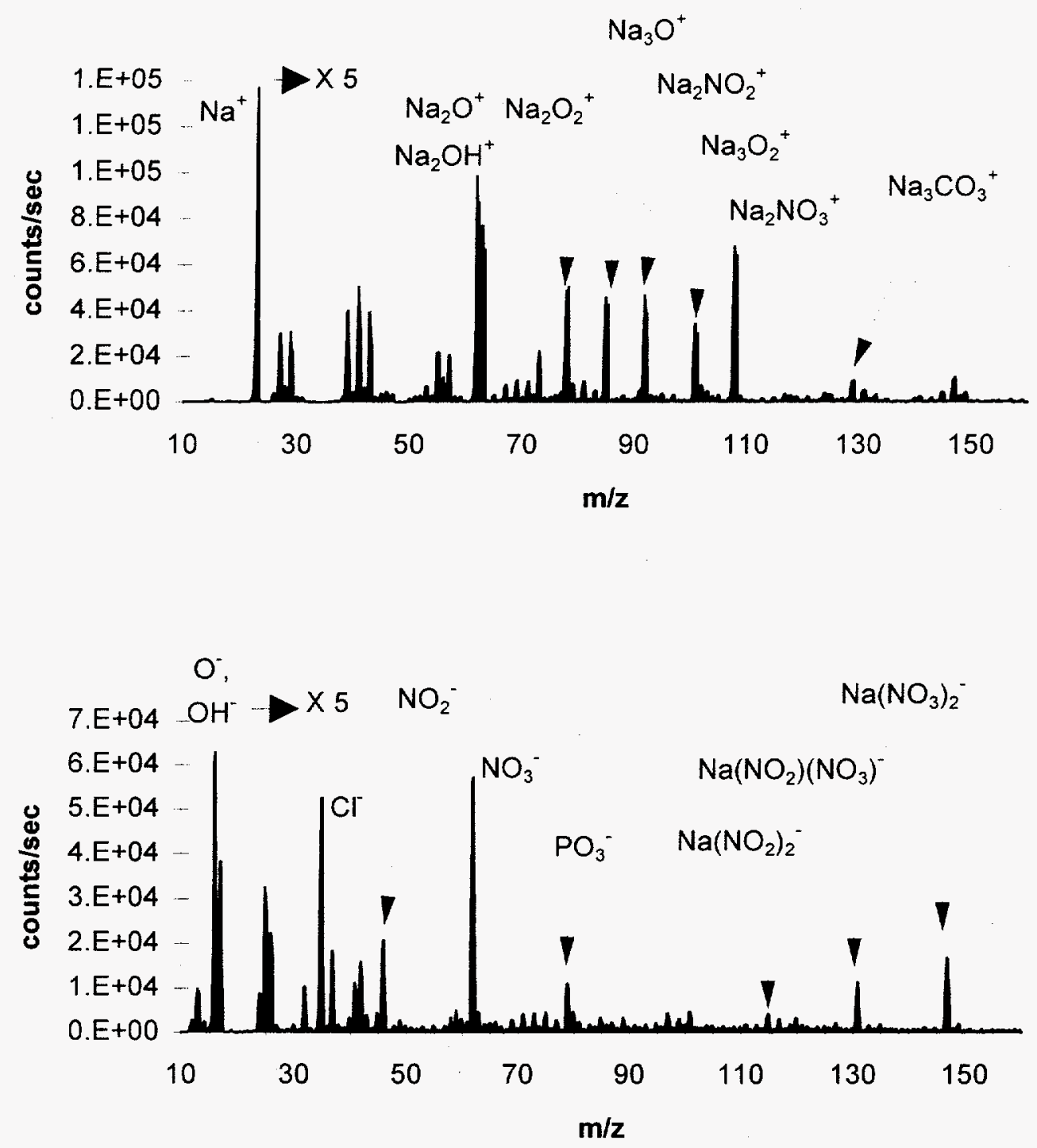

Figure $2 a$, top, and $2 b$, bottom 


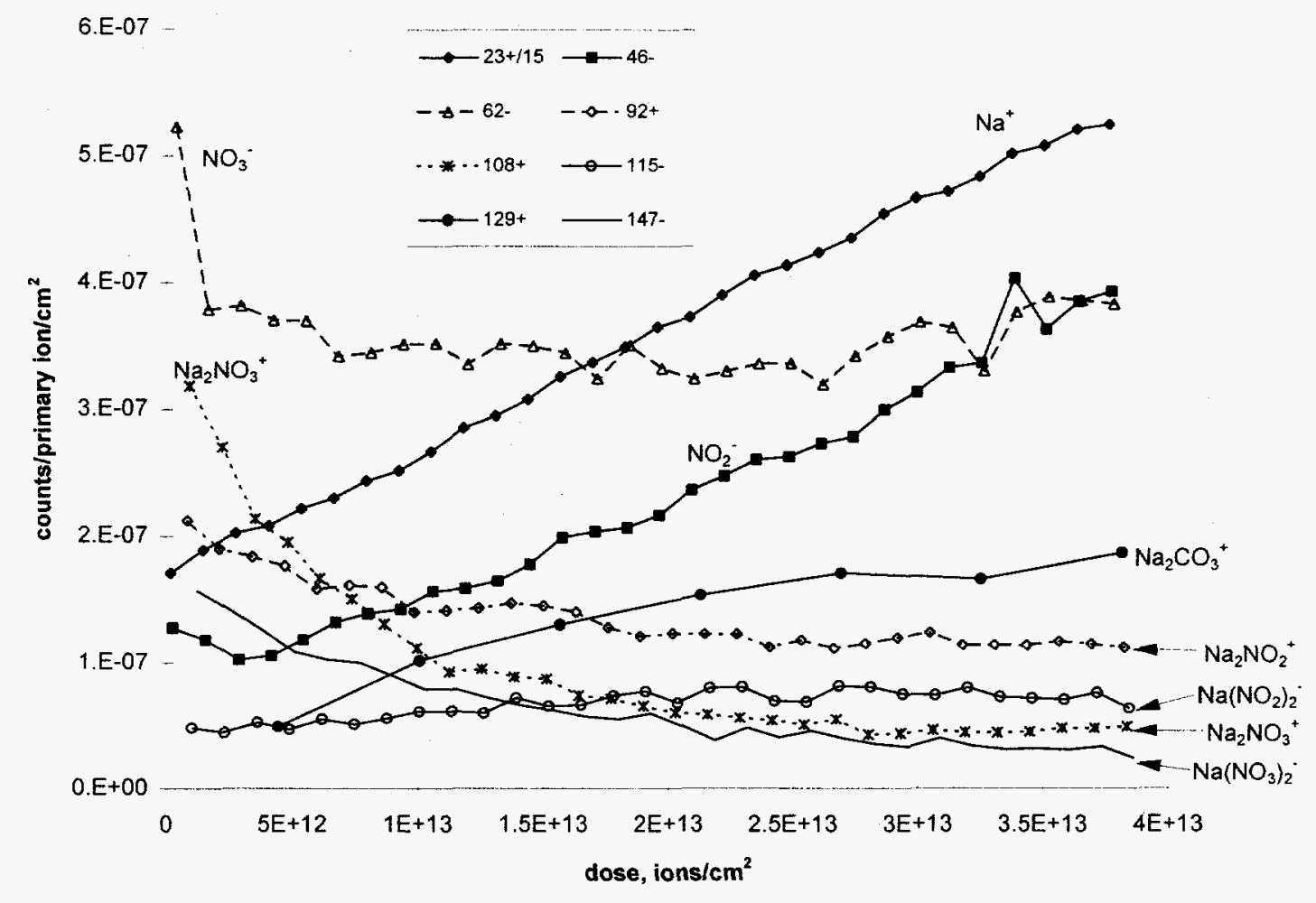

Figure 3. 


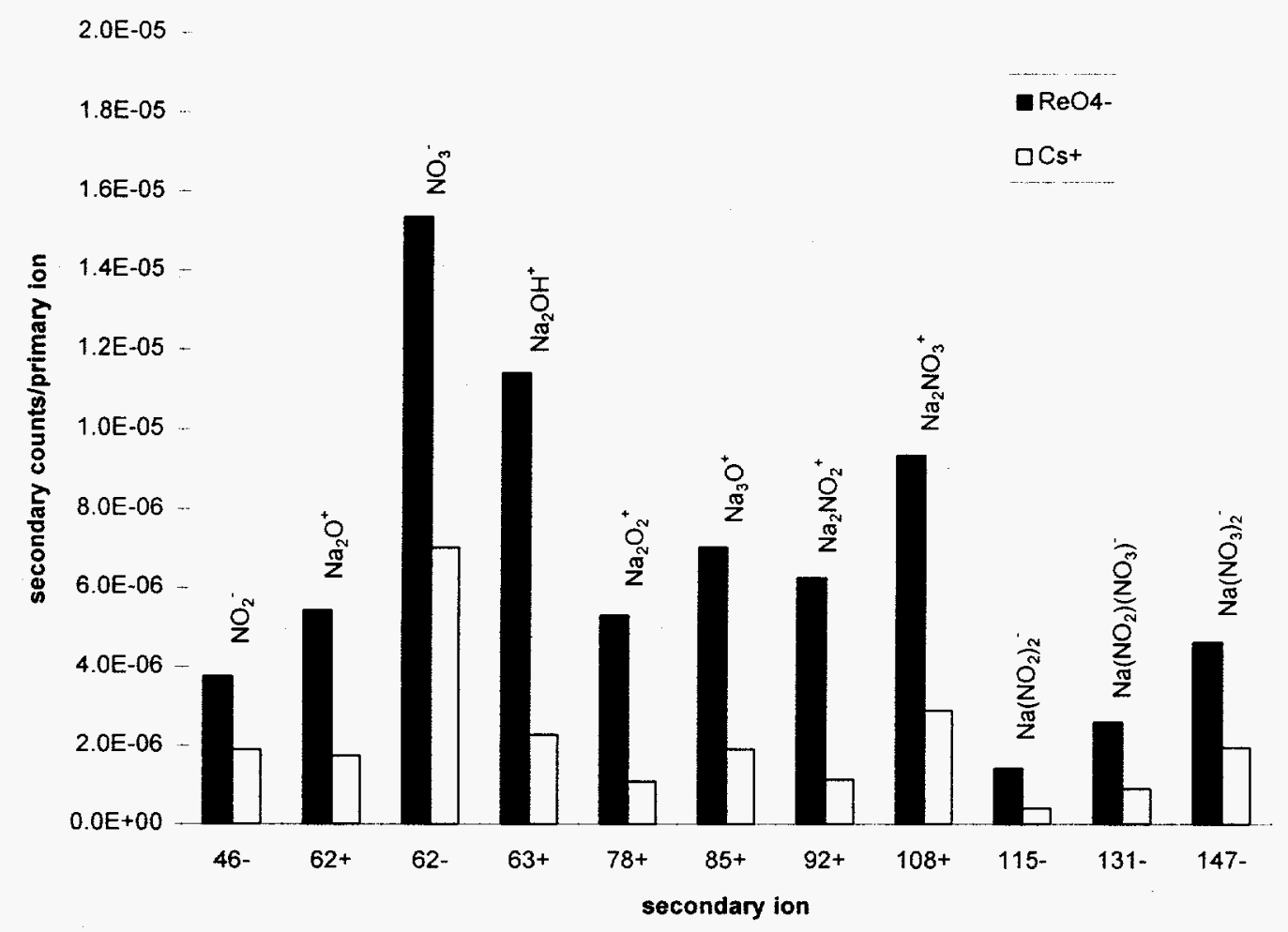

Figure 4. 


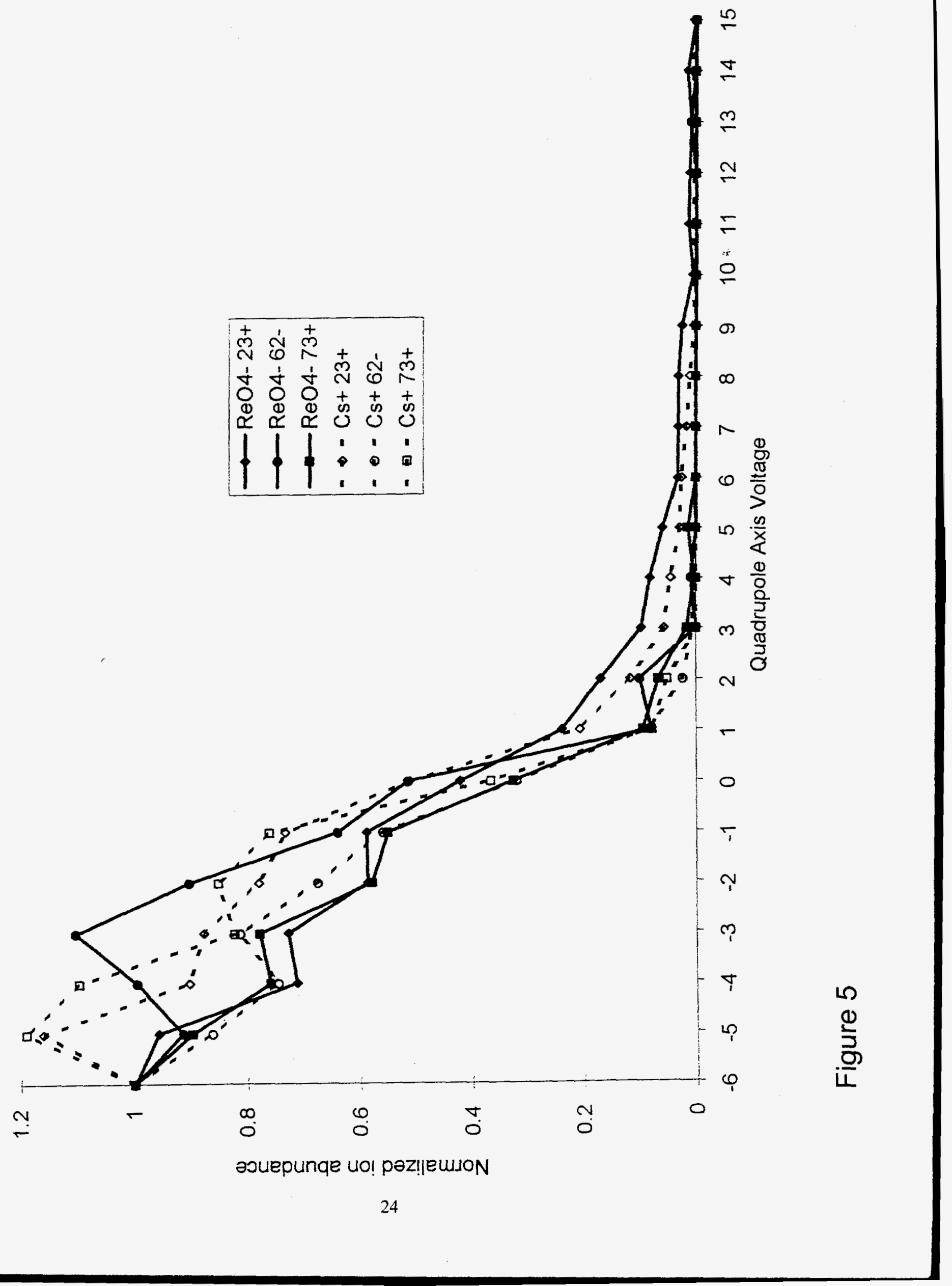

